Check for updates

MRC Biostatistics Unit, School of Clinical Medicine, University of Cambridge, Cambridge, UK

2 Institute for Infection and Immunity, St George's, University of London, London, UK

3 Department of Medicine, University of Cambridge, Cambridge, UK

4 Department of Epidemiology and Biostatistics, School of Public Health, Imperial College London, London, UK

Correspondence to: S Burgess sb452@medschl.cam.ac.uk Cite this as: BMJ2020;371:m4763 http://dx.doi.org/10.1136/bmj.m4763 Published: 10 December 2020

\section{Lightening the viral load to lessen covid-19 severity}

\author{
Adherence to separation measures is key
}

\author{
Stephen Burgess, ${ }^{1}$ David Smith, ${ }^{2}$ Julia C Kenyon, ${ }^{3}$ Dipender Gill ${ }^{4}$
}

Although the number of positive tests for severe acute respiratory syndrome coronavirus 2 (SARS-CoV-2) across many European countries has risen sharply in recent weeks, increases in the number of hospital admissions and deaths from covid-19 have not been as steep. The case fatality rate (the proportion of deaths per positive test) in the UK was lower in May and June than in March and April ${ }^{1}$ and seemed to steadily decline throughout July and August. ${ }^{2}$ Reductions were also observed in the early stages of the outbreak across many countries. ${ }^{3}$ Case fatality rates have varied in different countries, with relatively lower estimates observed in several African countries. ${ }^{4}$ Why have case fatality rates decreased, and how does this relate to measures used to control the epidemic?

\section{Possible reasons}

The first reason for reductions in the covid-19 case fatality rate is the changing demographic of cases. 5 Age is a strong predictor of covid-19 mortality. ${ }^{6}$ In many Western countries, the absolute number of cases in people older than 60 is increasing but the proportion of cases in that age group is decreasing. ${ }^{5}$ This indicates that public health measures to curb the spread of SARS-CoV-2 have been successful in reducing the relative burden of disease in older people, who are the most vulnerable demographic group.

The second reason is improved treatment. Systemic corticosteroids have been shown to improve outcomes in patients with covid-19, ${ }^{7}$ and clinical management of cases may also be improving through accumulated experience of the disease.

A third reason may relate to the number of infectious viral particles to which people are exposed at the point of infection (the "inoculum"). Although human challenge trials for SARS-CoV-2 are in early stages of development, studies of influenza A virus in humans have shown that initial exposure to a lower inoculum results in fewer and shorter symptoms as well as lower likelihood of viral shedding. ${ }^{8} 9$ This parallels animal experiments for influenza and for other viral diseases, ${ }^{10}$ and more recently for SARS-CoV-2 in Syrian hamsters ${ }^{11}$ and ferrets, ${ }^{12}$ in which inoculum size correlated with severity of ensuing disease. Viral load in patients with covid-19 has been shown to be greater in those with more severe illness. ${ }^{13}$

\section{Protective measures}

In humans, randomised trials of patients with viral upper respiratory tract infections have shown mask wearing reduces viral droplet emissions. ${ }^{14}$ Furthermore, masks have been found to reduce inhalation of particles. ${ }^{15}$ Several epidemiological studies have indicated mask wearing and other social distancing measures reduce the severity of covid-19. ${ }^{1617}$ Additionally, the use of masks has been shown in a laboratory setting to reduce both disease transmission and severity of SARS-CoV-2 infection in hamsters. ${ }^{18} \mathrm{~A}$ case series in humans comparing three transmission clusters with different degrees of social distancing showed differences in outcome severity between the clusters. ${ }^{19}$ Differences in social practices and living conditions that lead to variation in the inoculum may partly explain discrepancies in case fatality rates between countries.

The relation of inoculum size to infection severity has clear public health implications. As the northern hemisphere enters winter and more time is spent in confined spaces, it is important to emphasise that separation measures such as mask wearing, ventilation, and social distancing may reduce not only the spread of the virus but also disease severity. Even imperfect adherence to such measures is likely to be beneficial.

A question that remains open is the relative contribution of droplet versus aerosol transmission. ${ }^{20}$ Although measures such as screens and face shields intercept droplets, they are less likely to reduce aerosol transmission in poorly ventilated spaces. No approach can eliminate risk, but prioritising those measures that are most effective in reducing substantial viral transmission events enables a balance between managing the covid-19 pandemic and allowing society to continue to function.

Although the current high number of cases is alarming, the lower fatality rate is a sign that public health measures have had some success in protecting the most vulnerable, as well as potentially reducing disease severity in people who are infected. Ensuring adherence to control measures that reduce viral exposure is critical to minimising the severity of the pandemic, particularly given the severe harm that is caused by a hard lockdown.

Competing interests: We have read and understood BMJ policy on declaration of interests and declare that DG is employed part-time by Novo Nordisk, unrelated to the submitted article.

Provenance and peer review: Not commissioned, externally peer reviewed.

Dennis JM, McGovern AP, Vollmer SJ, Mateen BA. Improving survival of critical care patients with coronavirus disease 2019 in England: a national cohort study, March to June 2020. Crit Care Med 2020. [Epub ahead of print.] doi: 10.1097/CCM.0000000000004747 pmid: 33105150

2 Centre for Evidence-Based Medicine. The declining case fatality ratio in England. https://www.cebm.net/covid-19/the-declining-case-fatality-ratioin-england/

Pachetti M, Marini B, Giudici F, etal. Impact of lockdown on Covid-19 case fatality rate and viral mutations spread in 7 countries in Europe and North America. J Transl Med 2020;18:338.

doi: 10.1186/s12967-020-02501-x pmid: 32878627 
4 Chibwana MG, Jere KC, Kamng'ona R, etal. High SARS-CoV-2 seroprevalence in health care workers but relatively low numbers of deaths in urban Malawi. medRxiv2020;5:199. [Preprint.] doi: 10.12688/wellcomeopenres.16188.1 pmid: 32766597

5 Venkatesan P. The changing demographics of COVID-19. Lancet Respir Med 2020;8:e95. doi: 10.1016/S2213-2600(20)30461-6 pmid: 33035468

6 Pastor-Barriuso R, Pérez-Gómez B, Hernán MA, etalENE-COVID Study Group. Infection fatality risk for SARS-CoV-2 in community dwelling population of Spain: nationwide seroepidemiological study. BMJ 2020;371:m4509. doi: 10.1136/bmj.m4509 pmid: 33246972

7 Sterne JAC, Murthy S, Diaz JV, etalWHO Rapid Evidence Appraisal for COVID-19 Therapies (REACT) Working Group. Association between administration of systemic corticosteroids and mortality among critically ill patients with covid-19: a meta-analysis. JAMA 2020;324:1330-41. doi: 10.1001/jama.2020.17023 pmid: 32876694

8 Han A, Czajkowski LM, Donaldson A, etal. A dose-finding study of a wild-type influenza A(H3N2) virus in a healthy volunteer human challenge model. Clin Infect Dis 2019;69:2082-90. doi: 10.1093/cid/ciz141 pmid: 30770534

9 Memoli MJ, Czajkowski L, Reed S, etal. Validation of the wild-type influenza A human challenge model H1N1pdMIST: an A(H1N1)pdm09 dose-finding investigational new drug study. Clin Infect Dis 2015;60:693-702. doi: 10.1093/cid/ciu924 pmid: 25416753

10 Marois I, Cloutier A, Garneau É, Richter MV. Initial infectious dose dictates the innate, adaptive, and memory responses to influenza in the respiratory tract. / Leukoc Biol 2012;92:107-21. doi: $10.1189 / j$ lib.1011490 pmid: 22504848

11 Imai M, Iwatsuki-Horimoto K, Hatta M, etal. Syrian hamsters as a small animal model for SARS-CoV-2 infection and countermeasure development. Proc Natl Acad Sci U S A 2020;117:16587-95. doi: 10.1073/pnas.2009799117 pmid: 32571934

12 Ryan KA, Bewley KR, Fotheringham SA, etal. Dose-dependent response to infection with SARS-CoV-2 in the ferret model: evidence of protection to re-challenge.bioRxiv 2020:2020.05.29.123810.[Preprint.]

13 Liu Y, Yan L-M, Wan L, etal. Viral dynamics in mild and severe cases of COVID-19. Lancet Infect Dis 2020;20:656-7. doi: 10.1016/S1473-3099(20)30232-2 pmid: 32199493

14 Leung NHL, Chu DKW, Shiu EYC, etal. Respiratory virus shedding in exhaled breath and efficacy of face masks. Nat Med 2020;26:676-80. doi: 10.1038/\$41591-020-0843-2 pmid: 32371934

15 van der Sande M, Teunis P, Sabel R. Professional and home-made face masks reduce exposure to respiratory infections among the general population. PLoS One 2008;3:e2618. doi: 10.1371/journal.pone.0002618 pmid: 18612429

16 Greenhalgh T, Schmid MB, Czypionka T, Bassler D, Gruer L. Face masks for the public during the covid-19 crisis. BMJ 2020;369:m1435. doi: 10.1136/bmj.m1435 pmid: 32273267

17 Gandhi M, Beyrer C, Goosby E. Masks do more than protect others during covid-19: reducing the inoculum of SARS-CoV-2 to protect the wearer. J Gen Intern Med 2020;35:3063-6. doi: 10.1007/s11606-020-06067-8 pmid: 32737790

18 Chan JF, Yuan S, Zhang AJ, etal. Surgical mask partition reduces the risk of non-contact transmission in a golden Syrian hamster model for coronavirus disease 2019 (covid-19). Clin Infect Dis 2020;71:2139-49. doi: 10.1093/cid/ciaa644 pmid: 32472679

19 Guallar MP, Meiriño R, Donat-Vargas C, Corral O, Jouvé N, Soriano V. Inoculum at the time of SARS-CoV-2 exposure and risk of disease severity. Int Infect Dis 2020;97:290-2. doi: 10.1016/j.ijid.2020.06.035 pmid: 32553720

20 Wilson N, Corbett S, Tovey E. Airborne transmission of covid-19. BMJ2020;370:m3206. doi: 10.1136/bmj.m3206 pmid: 32819961 